\title{
Private development-based forest conservation in Patagonia: comparing mental models and revealing cultural truths
}

\author{
Christopher Serenari $^{1}, \underline{\text { M. Nils Peterson }}^{2}, \underline{\text { Yu-Fai Leung }}^{2}$, Paulina Stowhas $^{3}$, Tim Wallace ${ }^{2}$ and Erin O. Sills $^{2}$
}

\begin{abstract}
Private protected area (PPA) conservation agents (CA) engaging in development-based conservation in southern Chile have generated conflict with locals. Poor fit of dominant development-based conservation ideology in rural areas is commonly to blame. We developed and administered a cultural consensus survey near the Valdivian Coastal Reserve (RCV) and Huilo Huilo Reserve (HH) to examine fit of CA cultural truths with local residents. Cultural consensus analysis (CCA) of 23 propositions reflecting CA cultural truths confirmed: (1) a single CA culture exists, and (2) RCV communities were more aligned with this culture than HH communities. Inadequate communication, inequitable decision making, divergent opinions about livelihood impacts and trajectories, and PPA purpose may explain differences between CAs and communities. Meanwhile, variability in response between and within communities may reflect differing environmental histories. Private protected area administrations might use CCA to confront cultural differences and thereby improve their community interactions.
\end{abstract}

Key Words: Chile; cultural consensus; development; mental model; private protected area

\section{INTRODUCTION}

Development-based conservation began in the 1980s to allay conflict associated with nonparticipatory conservation enclosure policies (Ferraro 2001). One popular strategy, integrated conservation and development projects (ICDPs), replaced a fines and fences approach with support for eco-friendly commercial ventures (Hughes and Flintan 2001). They were first introduced by the World Wide Fund for Nature, eventually growing upwards of 300 projects around the world, taking in hundreds of millions of dollars in international biodiversity conservation funds (Hughes and Flintan 2001). In a protected area context, these ventures include designated resource extraction activities and ecotourism to alleviate poverty (Ferraro and Simpson 2005). They are underscored by the assignment of a commercial value (market and nonmarket) to people, flora, fauna, and places so local resource users do not degrade the ecological environment (West et al. 2006). Reviews of ICDPs are mixed (Hughes and Flintan 2001, Brechin et al. 2002). Chief criticisms of the ICDP model are that they offer temporary solutions and that most of their benefits are realized at the global rather than the local level (Brown 2003). Critics perceive ICDPs as overly ambitious and based on naive assumptions about social, political, and cultural dynamics at the local level (Wells and McShane 2004).

Private development-based conservation is an innovation within a global private protected area (PPA) movement (Stolton et al. 2014). In cooperation with local and global actors, some PPA owners use development-based conservation to prevent environmental degradation and material poverty on large scales (Bishop et al. 2002). Preliminary background investigation of PPA websites and documents, and conversations with PPA stakeholders, revealed PPA administrations in Chile procure goods and services from nearby communities and work closely with them to improve sustainability of traditional livelihoods, generate employment opportunities, and support economic and social development projects.
Accordingly, the Chilean private sector's incorporation of development-based conservation is analogous to ICDPs that began in the 1980s with similar purposes (Wells and McShane 2004). We argue that these PPA strategies perpetuate the hegemonic ideals supporting ICDPs. These ideals have been documented to include: biodiversity conservation is the primary end; there is an obligation to address the social and economic needs of communities whose traditional livelihood practices threaten protected area biodiversity; improved relationships between protected area managers and their neighbors are critical to achieve conservation goals; control or ownership of protected area resources will remain with protected area administrators; funding is received from external sources to achieve conservation or development goals; and market-based livelihoods help accomplish sustainable conservation and human development goals (Hughes and Flintan 2001).

Despite subjective claims about fruitful partnerships between PPA administrators and communities, local dissent over inequity, livelihood disruption, elitism, rising land costs, and land rights exists (Meza 2009, Wakild 2009, Holmes 2013; E. Corcuera, 2013, personal communication). Because believing local resident support is important, if not critical, to PPA conservation, management needs to find an appropriate balance between achieving protected area goals and addressing resident needs and aspirations (McShane et al. 2011). Private protected areas in Chile are being created in which forest-dependent cultures are colliding with contemporary land-tenure mechanisms (e.g., access restriction) and land-use projects, so the crux of conflict may be attributed to some semblance of "ontological struggles," in which a "single notion of the world, the human, civilization, the future, or even the natural" dominates all others, leaving little room for alternative realities (Escobar 2011:138). Acknowledging and engaging with alternative worldviews could lessen conflict and create a path toward sustainable solutions under various PPA regimes. One way to assess divides between worldviews is to examine intercultural differences between the development-based 
conservation cultural truths that stakeholders associate with ICDP projects.

There have been few attempts to measure intercultural differences within development-based projects in Chile, or elsewhere, because research has focused on measuring outcomes (McShane and Newby 2004). Because the deployment of an ICDP approach by large-scale PPA administrators in Chile is a comparatively new phenomenon, there is a particular need to characterize variation in the private development-based conservation domain across stakeholder groups and help facilitate an understanding of common and contrasting worldviews.

We began addressing this need with research using cultural consensus theory (Romney et al. 1986) to compare the knowledge, values, and beliefs of PPA conservation agents to those of local residents in Chile. Because cultural differences were identified as a prime source of natural resource-based conflict (Peterson et al. 2002, Escobar 2006), we conducted this exploratory study to uncover "culturally defined truths" (Paolisso 2007:130). We posit that because development-based conservation initiatives are driven by hegemonic ideologies inherent to biodiversity conservation (Escobar 2006) and development (Sachs 2010), points of agreement and divergence between governing private development-based conservation actors and the local residents with which they seek to engage will emerge.

Our broad intent then is to understand how a hegemonic development-based conservation ideology fits in the context of large-scale PPAs in Chile. Specifically, we examined differences in cultural truths among stakeholders associated with large-scale private biodiversity conservation and the creation of development pathways for residents upon whom PPAs have an impact. Owners and administrators of prominent large-scale PPAs in Chile declared community development a primary objective of their operations. Various scales of government in Chile facilitate this objective with tax breaks and competitive grants for communitydevelopment initiatives, while international organizations, such as the United Nations Development Program, provide additional support. In the Los Ríos region, these actors claim to simultaneously enhance local social and economic development of the rural communities that border their reserves and achieve native forest protection (Serenari 2014).

\section{Cultural difference}

Historically, the ICDP model has not adequately accounted for intercultural differences. The relative lack of attention to cultural difference can be a source of conflict and resistance from local residents for two reasons. First, market-based incentives, such as payment to local residents for goods to be sold by the protected area, direct protected area employment, and development of protected area ecotourism businesses typically limit possibilities for locals to seek their own path to achieve nature conservation and human well-being outside of global economic markets. This has led to claims that ICDPs endorse social engineering practices (West and Brockington 2006). In many rural communities near PPAs, livelihoods, encompassing both material and symbolic aspects (Bebbington 1999), are not wholly reliant on global economic markets. Cultural, economic, and ecological change wrought by forcing local economies and cultures into the dominant economic ideology and discourse sometimes stimulates local resistance, particularly when the changes interfere with nonmarket means of survival (Escobar 1996, Armesto et al. 2001). Intercultural differences and conflict may be most glaring between dominant conservation and development actors and indigenous groups when conservation and ICDP models promote "fortress conservation" (e.g., protected areas) in and around indigenous spaces (Coria and Calfucura 2012).

\section{Mental models and cultural consensus theory}

Comparing mental models, cognitively constructed "representations of reality" (Jones et al. 2011:47) that direct human interactions with the larger world, can help us understand cultural differences in a social-ecological context (Mathevet et al. 2011). Cultural consensus theory, one popular approach for measuring mental models, asserts consensus analysis reveals patterns of agreement (i.e., cultural truths) on mental models about a "coherently defined subject matter" (Weller and Romney 1988:9) or "knowledge domain" (Mathevet et al. 2011:43). This approach permits scholars "to make inferences about [informants'] differential competence in knowledge of the shared information pool constituting culture" (Romney et al. 1986:316). For example, a researcher might ask residents with subsistence agriculture livelihoods to list the ways they manage their natural resources. The more agreement there is among residents, the higher the scholar's confidence that there will be consistency among the larger population of interest and that a culturally defined truth about natural resource management is present. The assumptions associated with this theory are that "correspondence between the answers of any two informants is a function of the extent to that each is correlated with truth" (Romney et al. 1987:165) and that a type of mental model can arise from culture, in which information is cognitively processed, stored, and retrieved, (Jones et al. 2011).

Cultural consensus was employed to assess natural resource conflict at different scales. Johnson and Griffith (2010) used the cultural-consensus approach at the state level to discover how ideologies about natural cycles, tourist development, and pollution underscored North Carolina coastal resource conflicts. The approach was also used as a tool to find common ground between resource users and natural resource scientists and managers. Simeone et al. (2010) noted different perspectives on how to achieve long-term sustainability among indigenous fishers and Alaska's Copper River scientists and managers. They used the project and subsequent technical report to assess and compare stakeholder perspectives, establish common ground, and discover a pathway to equality and pluralism. Gatewood and Cameron (2009) used cultural consensus to identify resident perceptions of tourism development benefits and impacts in Turks and Caicos Islands. Research has yet to use cultural consensus as a tool to assess cultural differences in the context of private developmentbased conservation. Linking Johnson and Griffith's (2010) broadscale approach to cultural consensus analysis and the wider literature characterizing development-based conservation as a hegemonic process, we presumed there were dominant regional cultural truths among conservation agents in Los Ríos. We then used cultural consensus to examine the extent to which local residents agreed with or contested these truths. We chose this method because it requires relatively few participants and unites quantitative and qualitative ways to measure mental models, applying rigorous statistical analyses to structured interview or ethnographic data (Handwerker 2002, Stone-Jovicich et al. 2011). 
Cultural consensus is open to several data-gathering procedures (Rocha 2005). Commonly, semistructured interviews are linked with ethnography to inform a pile-sorting activity or true-false/ agree-disagree survey that collects the quantitative data needed for statistical analysis. Factor analysis is then employed to test three underlying assumptions of the formal model: a common truth exists; informant answers are independently given; and each informant has a fixed cultural competence over all questions of the same level of difficulty (Romney et al. 1986). Factor analysis can then be used to compare and contrast groups of interest, e.g., resident perceptions compared to those of natural resource managers.

\section{Study area}

Prior to colonization, Los Ríos was included in the territory of the Mapuche, the largest indigenous group in Chile. The native forests that once blanketed the region played a significant role within Mapuche culture, serving as a backdrop for small-scale agriculture, animal husbandry, hunting and gathering, physical well-being, and cosmological activities (Molares and Ladio 2012). Forests were common pool resources and the rules of daily life, including natural resource management, were commonly decided by the "lonko," i.e., chief (Molares and Ladio 2012). This form of top-down governance still exists in some Los Ríos locales, but communities usually had presidents and committees who represented resident interests during our study. Mapuche culture underwent "structural changes and cultural modifications" during Hispanic conquest (Faron 1962:1151) and colonial development schemes (Merino and Quilaqueo 2003). These cultural changes influenced how the Mapuche related to the land (Molares and Ladio 2012), perceived non-Mapuche (Merino and Quilaqueo 2003), and how non-Mapuche viewed Mapuche (Merino and Quilaqueo 2003).

The relatively recent regulation of human interactions with Los Ríos forests by governmental and other conservation actors may help shape cultural truths evaluated in this study. A large portion of Chile's economic expansion since the early 1970s is attributed to the exploitation of timber. Decree-Law 701 (i.e., 1974 Forest Law) enacted under Augusto Pinochet's reign was cited as a boon to the Chilean economy. Timber companies were greatly incentivized to purchase large tracts of public and private native forest and convert it to production forests (Klubock 2006). The biologically rich native Valdivian forest, a large remaining portion of which is in the region of Los Ríos, suffered pronounced ecological degradation as native forests were burned and replaced with fast growing exotic timber plantations, or were clear-cut for wood chip exports (Silva 1997).

This period also brought severe disturbance for rural peoples (Clapp 1998). Social impacts were extensive and intense. Many rural peoples were expelled from native forests that were purchased by timber companies. For those that remained, rapid forest clearing damaged traditional subsistence economies (Armesto et al. 2001, Klubock 2006). Entire communities became highly dependent on exploitive short-term seasonal timber employment (Klubock 2006). When the timber industry declined, many rural residents were left landless and without sufficient options for income or land for subsistence (Armesto et al. 2001). Emigration to urban areas and a decline in quality of life ensued (Armesto et al. 2001). Others continued to engage the state and timber companies in battles over land rights (Meza 2009). Efforts to address the issues of forest degradation, poverty, cultural deterioration, and emigration in these areas have been included in Chile's postdictatorship sustainable development path.

The maturing Chilean democracy of the early 1990s coincided with increased global attention to the concept of sustainable development. Sustainable development in Chile is an attempt to simultaneously achieve sustainable use of natural resources and meet economic and social priorities within a pro-market climate. Being a largely deregulated state, attempts by environmentalists and critics of neoliberal market ideology to influence sustainable development in Chile have mainly fallen short politically (Carruthers 2001). However, growing concerns over social equity and environmental degradation eventually yielded new initiatives that departed from unbridled timber operations. In 2002, for example, the Chilean System for Sustainable Forest Management Certification, affiliated with the Programme for the Endorsement of Forestry Certification, was created in an attempt to create global demand for sound environmental, economic, social, and institutional timber company practices (Barton and Román 2012). In some cases, the resultant conversion of remaining native forests, formerly owned by now defunct timber companies, into large PPAs and tourist destinations are changing the fabric of forest communities again. Three large-scale PPAs were formed in the region between 1989 and 2004: Oncol Park (OP), owned by timber and pulp company Arauco Corporation; Valdivian Coastal Reserve (RCV), owned by The Nature Conservancy (TNC); and Huilo Huilo Reserve (HH), owned by a Chilean tycoon.

Some communities benefited economically from PPAs, employing sustainable development principles and the progression from a timber-to-tourism economy. One example is the conversion of Neltume, the largest commune near the 100,000 ha HH property, from a timber shantytown to a growing tourist destination. Because of HH's tourism, Neltume experienced new construction and economic growth after 2002. However, benefits from PPAs do not extend to all communities or residents upon which they had an impact. Consequently, these communities in Los Ríos, particularly Mapuche, continue to seek out ways to transcend a substandard quality of life and reduce uncertainty, risk, and emigration caused by lack of income opportunities. Many rural residents continue to engage in historical, but greatly diminished, land-use practices, mainly small-scale agriculture and animal husbandry, and seek ways to fit into a market economy within "a highly unequal Chilean society" (Meza 2009:152).

The creation of PPAs adds complexity to rural dynamics in Los Ríos because there is a history of using nature conservation as a political tool to gain territorial control in Chile (Meza 2009). Rural residents already struggle against uneven development and policies that promote other types of rural change, including road building and hydroelectric dams. Many in our study area, mainly Mapuche, continue to continue to fight economic and political marginalization and to reclaim lands lost during colonization and military rule.

\section{METHODS}

\section{Selection of respondents}

The research design employed purposive sampling and we focused on subjects that were engaged with RCV and $\mathrm{HH}$. We defined "engaged" based on two screening criteria: involvement in 
community discussions about the PPA or direct engagement with PPA conservation agents. Key and engaged informants tended to be regulatory and academic authorities, current and former PPA employees and contractors, ecotourism guides, business owners, teachers, community decision makers, and life-long residents. After interviewing key informants, we used snowball sampling to find engaged residents in communities earmarked by RCV (Huape, Chaihuán, Cadillal, and Huiro) and HH (Neltume and Puerto Fuy) for outreach. Preliminary fieldwork and cultural consensus literature provided support for using a purposive locally based sampling approach. It was the best way to: (1) ensure that respondents encountered the dominant ideology in question and (2) capture "culture" (Handwerker and Wozniak 1997). This approach also helped overcome problems associated with sampling concealed individuals, those who acted criminally in protest against PPAs or were isolated or marginalized, for example (Faugier and Sargeant 1997).

\section{Proposition development}

We designed a culturally correct questionnaire (Paolisso 2007) based on the PPA conservation agents' cultural truths about development-based conservation in Los Ríos. We aimed to compare the fit of conservation agents' cultural truths with those of engaged local residents. A one-sided assessment of cultural truths, using a questionnaire designed to represent conservation agents, was particularly apropos in this context because it facilitated comparisons between a hegemonic ideology manifested as cultural truths and the perspectives of stakeholders upon which it had an impact, who may not share the same cultural truths. This approach to cultural consensus analysis, however, limits our ability to make inferences about consensus within all potential stakeholder groups because not all perspectives were represented in questionnaire development.

Interviews with 22 key informants conversant about PPAs in Los Ríos between May and July 2013 informed the questionnaire. Transcriptions of these interviews revealed commonly mentioned statements about PPAs, including land use and ecological protection; reasons for creation; PPA-community relations; economic expectations; tourism development; free market values; conflict; community benefits and change; and PPA role in the achievement of local resident well-being. Twenty-three propositions were then written from the perspectives of conservation agents, who tended to reflect prevailing global thinking about development-based conservation, and worded in agree/disagree format. We used a binary response option because it performs better than paired-comparison and triadiccomparison questionnaires (Reyes-Garcia et al. 2004). Wording adjustments were made by research team members with experience conducting interviews in rural Los Ríos to enhance the clarity of the questionnaire prior to its deployment.

\section{Survey administration}

We administered the survey and conducted additional semistructured interviews between late June and early August 2013. We briefed participants that there were no right or wrong answers to the survey and individual and confidential opinions were being sought. We encouraged respondents to consider each proposition in general and to answer quickly; however, they were also encouraged to offer any supplemental thoughts after completing the questionnaire.

\section{Analysis}

We surveyed and interviewed 52 people, 45 community members and 7 conservation agents, and entered survey data into an Excel database by interview identification number. We employed UCINET (V6.0) to conduct cultural consensus analysis. UCINET uses principal component analysis to produce eigenvalues, i.e., a value indicating how spread out the data is from a nonzero vector, eigenvector, that best fits the data, and to calculate the dimensionality of the solution.

According to Romney et al. (1987), a ratio of the first eigenvalue less than three times greater than the second and a negative or low (less than 0.5) competency score suggest multiple cultures and weak cultural competence, respectively. In this study, a sample eigenratio of greater than or equal to 3.00 would suggest a monolithic private development-based conservation culture. A sample competency score less than 0.5 would equate to shared beliefs within groups about the culture. Statistical power is assessed differently with cultural consensus analysis than many other quantitative methods and, based on best practices (Romney et al. 1986:326). Our sample size was high, yielding a confidence level of at least .95 .

Employing Bayes' Theorem to infer correct answers, UCINET also produces an answer key, specifying the probability of culturally correct/true answers for all propositions (see Weller 2007 for further discussion). We performed cultural consensus analysis on the overall sample, conservation agents, and RCV and $\mathrm{HH}$ communities individually to examine between-group differences. Cultural consensus analysis of conservation agents' responses served as a face validity check of our dominant ideology assumption.

Additionally, for those propositions that had disagreements between conservation agents and communities, we plotted percent agreement with propositions for which at least one group disagreed. We analyzed and coded our interview data in QSR International's NVivo (V10) qualitative data analysis software and used thematic content analysis to derive our codes (Anderson 2007). We used IBM SPSS (V21.0) to calculate frequency distributions, univariate analysis, and Spearman correlations to compare answer keys.

\section{RESULTS}

\section{Sample characteristics}

Most participants from the $\mathrm{HH}$ area were Chilean $(n=21,91 \%)$, male $(n=16,70 \%)$, achieved postprimary education $(n=12,52 \%)$, were between 35 and 45 years $(n=8,35 \%)$, and earned a monthly income of Ch\$250 million ( $n=18,78 \%$ ). Participants from RCV communities were primarily Mapuche $(n=12,57 \%)$, male $(n=$ $14,64 \%)$, over 46 years of age $(n=14,64 \%)$, had a primary education ( $n=11,55 \%)$, and reported monthly income of less than CLP\$250mil $(n=18,90 \%)$.

\section{Cultural consensus}

\section{Verification of assumption}

Analysis indicated cultural consensus existed among conservation agents across 23 propositions, confirming our underlying assumption that a dominant conservation-agent culture existed. An eigenratio greater than $3.00($ eigenratio $=4.04)$ and high competency score (.67) suggest a cultural truth and 
strong degree of shared cultural understanding, respectively (Table 1).

Table 1. Cultural consensus analysis for dichotomous data. (CA $=$ conservation agents, $\mathrm{HH}=$ Huilo Huilo Reserve, $\mathrm{RCV}=$ Valdivian Coastal Reserve)

\begin{tabular}{lcccc}
\hline \hline Measure & $\begin{array}{c}\mathrm{CAs} \\
(\mathrm{n}=7)\end{array}$ & $\begin{array}{c}\mathrm{HH} \\
\text { Communities } \\
(\mathrm{n}=23)\end{array}$ & $\begin{array}{c}\text { RCV } \\
\text { Communities } \\
(\mathrm{n}=22)\end{array}$ & $\begin{array}{c}\text { Sample } \\
(\mathrm{n}=52)\end{array}$ \\
\hline Eigenratio & 4.04 & 1.90 & 2.37 & 2.85 \\
Mean Competence & .67 & $.48(.34)$ & $.56(.18)$ & $.52(.26)$ \\
(SD) & $(.22)$ & & & \\
\hline
\end{tabular}

\section{Communities}

Disaggregation of community groups allowed us to determine which communities had cultural truths most similar to conservation agents. Results indicated weak consensus for RCV (eigenratio $=2.37$ ) and $\mathrm{HH}$ (eigenratio $=1.90)$ communities. Similarly, lower competency scores for RCV (0.56) and HH (0.48) suggest variance within these communities, though RCV respondents had higher correspondence with conservation agents' cultural truths (Table 1). Comparison of intercorrelations among answer keys illustrates RCV communities had a stronger association with the conservation agents answer key (0.62), whereas $\mathrm{HH}$ communities had much weaker relationships with conservation agent $(0.35)$ and RCV (0.35) answer keys.

\section{Explaining cultural differences}

The variability between groups indicated by low eigenratios and competency scores was reflected in our thematic analysis of interview transcripts. One quote from a former corporate logger and RCV ranger summarized divisions within our communities that may hinder consensus:

...when the reserve arrived, the town was divided. Some
said it was good, others that it was bad, because they were
used to [working for] timber companies... a lot of people
were working...there wasn't a future in [timber]...So,
there were people who agreed and others who didn't.

The same sentiment of differences among locals was found among the HH communities. One member of Neltume stated:

\section{I think they agree with what the park does. It's just that} now a lot of people are out of jobs. So people are divided.

A Puerto Fuy resident echoed views on the presence of community divisions noting:

$$
\begin{aligned}
& \text {... the community here is not very unified, that's the } \\
& \text { reality. There's an enormous lack of unity. }
\end{aligned}
$$

Fourteen culturally true statements were observed for the sample (Table 2). Examining communities individually, at least one disagreed with conservation agents on nine propositions, with the $\mathrm{HH}$ group being the group disagreeing with conservation agents most often (Figure 1). On seven occasions (\#1, \#3, \#5, \#6, \#8, $\# 13$, \#15) the HH group disagreed with conservation agents, whereas RCV communities disagreed four times (\#4, \#8, \#13, \#16). Only twice (\#8, \#13) did RCV and $\mathrm{HH}$ communities disagree with conservation agents on a proposition at the same time. Responses given by locals were compared with conservation agents to illustrate their divergent answers to propositions (Table 3). Several themes emerged from these quotes. Local residents linked HH ownership with corruption, forest degradation, selfaggrandization, and secrecy. Conversely, local residents linked RCV owners with candor, cooperation, forest protection, and vigorous promotion of community organization, local traditions, empowerment, and collective action.

Fig. 1. Percent agreement with propositions that have disagreement by at least one group. (CA = conservation agents, $\mathrm{HH}=$ Huilo Huilo Reserve communities, $\mathrm{RCV}=$ Valdivian Coastal Reserve communities)

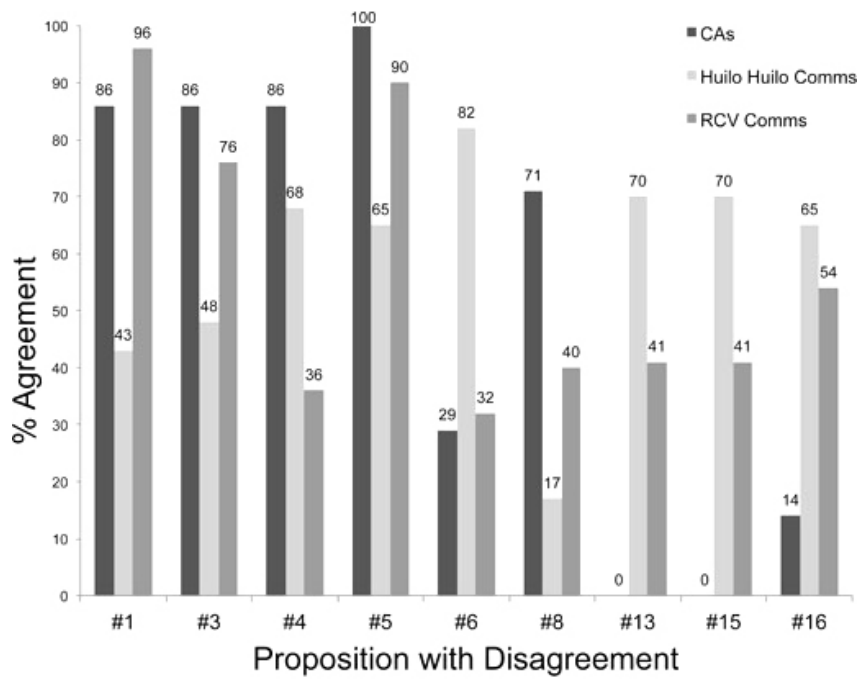

\section{DISCUSSION AND IMPLICATIONS}

\section{Cultural consensus and difference}

Our analysis suggests local residents do not share the dominant cultural model with conservation agents about large-scale private development-based conservation. Unexpectedly, however, RCV communities (primarily Mapuche) agreed more often with conservation agents on the 23 propositions than $\mathrm{HH}$ communities (primarily Chileans), and offered more positive perceptions of their respective PPA. Gaps in communication, inequitable decision making, divergent opinions about livelihood impacts and trajectories, and PPA purpose tended to underscore differences between conservation agents and resident responses. These results may originate from varying degrees of conservation agent expertise and flexibility working with communities (Hackel 1993) and, therefore, an improved ability to understand and effectively interact with other cultures. Unlike the other PPAs in our study, TNC seems to have benefited from their partnership with WWF, an organization that adopted a policy of recognizing community rights and needs, particularly indigenous ones, in 1996. There is a need, however, to better understand the drivers of our findings. Future research should more deeply explore the beliefs, strategies, and mechanisms by which PPA administrators approach and engage private development-based conservation because each ownership type will likely engage with issues of poverty and biodiversity in very different ways (Adams et al. 2004). 
Table 2. Large-scale private protected area $(\mathrm{PPA})$ propositions and their culturally correct answers. $(\mathrm{CA}=$ conservation agents, $\mathrm{HH}=$ Huilo Huilo Reserve, RCV = Valdivian Coastal Reserve)

\begin{tabular}{|c|c|c|c|c|}
\hline \multirow[b]{2}{*}{ Propositions } & \multicolumn{4}{|c|}{ Culturally Correct Answers } \\
\hline & $\begin{array}{l}\text { Sample } \\
(\mathrm{n}=52)\end{array}$ & $\begin{array}{l}\text { CAs } \\
(n=7)\end{array}$ & $\begin{array}{l}\text { Huilo Huilo } \\
(\mathrm{n}=23)\end{array}$ & $\begin{array}{c}\mathrm{RCV} \\
(\mathrm{n}=22)\end{array}$ \\
\hline 1. The reserve does a good job of protecting forests from harm. & $\mathrm{T}$ & $\mathrm{T}$ & $\mathrm{F}$ & $\mathrm{T}$ \\
\hline $\begin{array}{l}\text { 2. The reserve should be accessible for limited harvesting activities by } \\
\text { community members. }\end{array}$ & $\mathrm{T}$ & $\mathrm{T}$ & $\mathrm{T}$ & $\mathrm{T}$ \\
\hline $\begin{array}{l}\text { 3. Because of the reserve, communities near the reserve have changed } \\
\text { their behavior to better conserve nature. }\end{array}$ & $\mathrm{T}$ & $\mathrm{T}$ & $\mathrm{F}$ & $\mathrm{T}$ \\
\hline $\begin{array}{l}\text { 4. Traditional livelihoods (e.g., livestock raising, timber extraction) have } \\
\text { caused significant local environmental degradation. }\end{array}$ & $\mathrm{T}$ & $\mathrm{T}$ & $\mathrm{T}$ & $\mathrm{F}$ \\
\hline 5. The reserve was created to protect forests from degradation. & $\mathrm{T}$ & $\mathrm{T}$ & $\mathrm{F}$ & $\mathrm{T}$ \\
\hline 6. The reserve was created to make money from tourism. & $\mathrm{F}$ & $\mathrm{F}$ & $\mathrm{T}$ & $\mathrm{F}$ \\
\hline $\begin{array}{l}\text { 7. The reserve completing its objectives depends on having good } \\
\text { relations with the neighboring communities. }\end{array}$ & $\mathrm{T}$ & $\mathrm{T}$ & $\mathrm{T}$ & $\mathrm{T}$ \\
\hline 8. The reserve keeps communities well informed of reserve operations. & $\mathrm{F}$ & $\mathrm{T}$ & $\mathrm{F}$ & $\mathrm{F}$ \\
\hline $\begin{array}{l}\text { 9. The reserve should provide free environmental education programs } \\
\text { for local schools. }\end{array}$ & $\mathrm{T}$ & $\mathrm{T}$ & $\mathrm{T}$ & $\mathrm{T}$ \\
\hline 10. The reserve should influence community development. & $\mathrm{T}$ & $\mathrm{T}$ & $\mathrm{T}$ & $\mathrm{T}$ \\
\hline $\begin{array}{l}\text { 11. Communities should have less influence over reserve management } \\
\text { decisions. }\end{array}$ & $\mathrm{F}$ & $\mathrm{F}$ & $\mathrm{F}$ & $\mathrm{F}$ \\
\hline $\begin{array}{l}\text { 12. Partnerships with reserves will help communities influence } \\
\text { government affairs. }\end{array}$ & $\mathrm{T}$ & $\mathrm{T}$ & $\mathrm{T}$ & $\mathrm{T}$ \\
\hline $\begin{array}{l}\text { 13. The reserve should not generate revenue for community } \\
\text { development. }\end{array}$ & $\mathrm{F}$ & $\mathrm{F}$ & $\mathrm{T}$ & $\mathrm{T}$ \\
\hline 14. The reserve is not responsible for creating local jobs. & $\mathrm{F}$ & $\mathrm{F}$ & $\mathrm{F}$ & $\mathrm{F}$ \\
\hline $\begin{array}{l}\text { 15. Tourism-based livelihoods should replace traditional livelihood } \\
\text { options (e.g., farming, timber industry work, livestock raising) as the } \\
\text { main source of household income. }\end{array}$ & $\mathrm{F}$ & $\mathrm{F}$ & $\mathrm{T}$ & $\mathrm{F}$ \\
\hline 16. Households should compete for tourism revenue opportunities. & $\mathrm{F}$ & $\mathrm{F}$ & $\mathrm{F}$ & $\mathrm{T}$ \\
\hline $\begin{array}{l}\text { 17. Reserve-based tourism is the best way to ensure the well-being for } \\
\text { most community members. }\end{array}$ & $\mathrm{F}$ & $\mathrm{F}$ & $\mathrm{F}$ & $\mathrm{F}$ \\
\hline $\begin{array}{l}\text { 18. Managers cannot make all locals happy with reserve management } \\
\text { decisions. }\end{array}$ & $\mathrm{T}$ & $\mathrm{T}$ & $\mathrm{T}$ & $\mathrm{T}$ \\
\hline $\begin{array}{l}\text { 19. To have a prosperous tourism economy, historical community } \\
\text { relations with nature must change. }\end{array}$ & $\mathrm{T}$ & $\mathrm{T}$ & $\mathrm{T}$ & $\mathrm{T}$ \\
\hline $\begin{array}{l}\text { 20. Communities that want to engage in tourism will benefit the most } \\
\text { from the reserve. }\end{array}$ & $\mathrm{T}$ & $\mathrm{T}$ & $\mathrm{T}$ & $\mathrm{T}$ \\
\hline $\begin{array}{l}\text { 21. Communities working with the reserve to apply for community } \\
\text { project funds benefit the most from the reserve. }\end{array}$ & $\mathrm{T}$ & $\mathrm{T}$ & $\mathrm{T}$ & $\mathrm{T}$ \\
\hline $\begin{array}{l}\text { 22. The reserve should work with external organizations to help } \\
\text { improve the well-being of communities. }\end{array}$ & $\mathrm{T}$ & $\mathrm{T}$ & $\mathrm{T}$ & $\mathrm{T}$ \\
\hline $\begin{array}{l}\text { 23. The reserve is doing enough to provide the basis for people's } \\
\text { livelihoods and the goods and services necessary for achievement of } \\
\text { human well-being. }\end{array}$ & $\mathrm{F}$ & $\mathrm{F}$ & $\mathrm{F}$ & $\mathrm{F}$ \\
\hline
\end{tabular}

Variance among community responses may be explained by historical differences between dependence on one industry near $\mathrm{HH}$ and the lived indigenous experience near RCV. At the time of our study, more formally educated and higher income earning $\mathrm{HH}$ communities were transitioning from extreme dependence on unsustainable timber extraction into a condition of extreme dependence on a privately established nature tourism industry. In Neltume and Puerto Fuy, intense timber extraction was, and now nature tourism is, essentially the only subsistence option, prolonging a cycle of economic dependence and social domination (Mowforth and Munt 2009). On the other hand, RCV community sentiments suggest an autonomous disposition and subsistence livelihood diversification strategy that dates back to precolonization. These ends are likely a product of centuries of territorial, social, and political conflict, impoverished conditions (including low income and minimal formal education), detachment from external markets, and use of land and sea to support material and symbolic aspects of life (Meza 2009; I. Ponce and C. Frêne, 2007, unpublished manuscript). Nature tourism, like bygone employment with corporate logging, is just one activity within diverse livelihood portfolios, rendering TNC's efforts to support local residents helpful, but not mandatory for well-being (Serenari 2014).

The heterogeneity of local communities in this study complicates debates about private development-based conservation. Variability in responses within communities may be attributed to (1) differences between local expectations of PPA-people relations grounded in competing collective and individual visions of rural 
Table 3. Contrasting views of locals and conservation agents about private protected area (PPA) propositions (hegemonic ideologies).

\begin{tabular}{lll}
\hline \hline Proposition & $\begin{array}{l}\text { Huilo Huilo Reserve (HH) Locals' } \\
\text { Response }\end{array}$ & $\begin{array}{l}\text { Valdivian Coastal Reserve (RCV) } \\
\text { Locals' Response }\end{array}$ \\
\hline $\begin{array}{ll}\text { 1. The reserve does a good job of } \\
\text { protecting forests from harm. }\end{array}$ & $\begin{array}{l}\text { "They toss away trees that are 25 } \\
\text { meters tall! Tepas, laurels, mañíos, }\end{array}$ & Agreed with agents. \\
& $\begin{array}{l}\text { they cut them entirely! That is not } \\
\text { management of the forest. [The }\end{array}$ & $\begin{array}{l}\text { forest] management plans, there are } \\
\text { parts where a little extraction is } \\
\text { done, but only in a few places." }\end{array}$
\end{tabular}

3. Because of the reserve, communities near the reserve have changed their behavior to better conserve nature.

4. Traditional livelihoods (e.g., raising livestock, timber extraction) have caused significan local environmental degradation. counted six full trucks in one day filled with rauli trees...he is supposed to take care of it, protect it..."

“...there's the fact that people don't Agreed with agents. ike excessive exploitation of the land, but they also need to work. So sometimes the first is overlooked in favor of the latter."

"...there's still a consciousness rooted in the timber business."

Agreed with agents.

"I think that people always took wood from the forest, but they never took more than what they needed, they never sold it. It was a sustainable way of extraction." "[Livestock] do no harm to trees."

"[The reserve is for] a market

5. The reserve was created to protect forests from degradation (responses overlap with \#6).

6. The reserve was created to make money from tourism.

8. The reserve keeps communities well informed of reserve operations.

13. The reserve should not generate revenue for community development. purpose over a conservation purpose."

"I really think it's for tourism, for only [the owner] to earn money."

"I've never seen [Huilo Huilo staff] in a meeting with the community, or asking them, like, "We have this project, what do you think?'...things like that, no."

"...it's as if [the owner] were the grand lord here and he said: 'I'll build wherever I want and people just have to accept it.",

"I wouldn't ask [Huilo Huilo] for their help, it would make me feel corrupted."

"[The owner] had a meeting and told everyone he would give them paint for free so they would paint their houses in the way he wanted, but the people said: 'No.'”
Agreed with agents.

Agreed with agents.

"No one informs us of anything." development enterprise...

"...we create a good relationship with them by being good neighbors. We keep our doors open to then, we listen to them...we always have to be ready to hear all their complaints, needs, and questions they might have."

"[The Nature Conservancy (TNC)] should be more communicative."

"The communities near the park are used to do things on their own, they won't request anything from the reserve."

"No, there's no way [TNC] would give money."

"The mission of the foundation is to contribute to the conservation rainforest and its resources...'

"Most people thought that Huilo Huilo is a tourism company, but $\mathrm{HH}$ is not a tourism enterprise, it is a territorial sustainable

"We work hand by hand with the neighbors committee and many of the collectives here."

"We [Huilo Huilo] give $90 \%$ of the jobs in the area."

"We [Huilo Huilo] built the fire station of Puerto Fuy, we work with
"Before...people crossed [the River Fuy] with machetes, chainsaws, axes, and became frenzied with getting as much wood as possible. Nowadays, no one does that. People have changed their mindset."

"They now see [the forest] as valuable asset, more than just a source for fuel..."

"...there are resources that are being regulated, like...cattle...which were identified as a menace to the area..."

"We think, as a principle, that if a family used to raise animals within the park or chopped firewood...and today we employ them, this means a positive impact on the forest..." the fire station of Neltume, we built the radio station, we give financial help to a local folk band, give direct advice on how to tend to different parks in the town. We also built a bike road, and many other things like that.' 
15. Tourism-based livelihoods should replace traditional livelihood options (e.g., farming, timber industry work, raising livestock) as the main source of household income.
"I switched to tourism because there was no other option. It is our future."
"[TNC] insisted, for instance, in projects that . you can live not only development] were implemented [by from the sea, or from the hills, there Huilo Huilo], were adapted to the are a million things that one can do, local reality, committing to

and starting from projects you can conservation and the local develop [on your own]."

"If it wasn't for the reserve, we wouldn't have the money needed to better our quality of life."
"This community is doing better economically than other places. We have many different ways to make a living, with the mussels, the wood, the tourism, fishing, etc."
16. Households should compete for tourism revenue opportunities. (Interviewees associated competition for funds with stratification of PPA tourism benefits; essentially, winners and losers. We have included quotes that highlight this relationship because interviewees did not directly address competition.) “...if [residents] can't get the means “...I'm a little unpleased because to prepare to work with tourism, what is it good for?"

\section{[RCV administrators] help} associations, but not individual people..." communities...with tourism being the main economic activity. That doesn't mean that we couldn't have other activities, but tourism was the main one."

"I think that it is fundamental that protected areas and other foundations, like in this case TNC, and the state, provide funding to capacitate [local people so they can] create infrastructure so that they can effectively incorporate other activities besides the traditional ones to create income."

"We have supported the creation of a local agricultural and forestry cooperative so they can work in the restoration project using some areas, and obtaining an income that wasn't in their old scheme..." development and worldviews (Pratt 2012), and (2) aggregating communities with different local realities for our analysis. For instance, the elimination of traditional timber livelihoods, a scarcity of capital to fully engage tourism on one's own terms, and divided loyalty to a powerful and allegedly polarizing PPA owner may contribute to the divisions we uncovered within $\mathrm{HH}$ communities. Communities and local dynamics are neither homogenous nor static, and decision makers should approach conservation and development policy with these notions in mind (Yung et al. 2003). Our results do suggest, though, that PPA administrations may determine how heterogeneity has an impact on their goals and how they can bridge divisions within communities. Our results illustrate that pooling resources through the encouragement and development of community cooperatives and refining rather than completely supplanting traditional livelihood practices with sustainable techniques are useful approaches.

\section{Implications}

The results suggest important implications for scholars, practitioners, and decision makers engaging with private development-based conservation, particularly those currently engaging the shared or dominant cultural model in Los Ríos. We anticipate each will be interested in exploring why indigenous community cultural truths matched with those of the conservation agent group better than the nonindigenous Chilean group. Prior research on this topic tends to stress cultural differences between rural resident perspectives, particularly indigenous ones, and conservation-development actors (Colchester 1994, Peters 1998, Meza 2009, Coria and Calfacura 2012). With much attention given to fostering local participation in development-based conservation projects, future scholarly inquiries should consider identifying under what conditions and contexts local perspectives agree and diverge with PPA conservation agents because assumptions about ideological differences with indigenous groups may be overstated. Likewise, some conservation agents might need to consider equally distributing the attention they give to local communities, avoiding favoring one over another without sound logic of why they are doing so.

Secondly, our findings suggest CCA may provide a useful tool for highlighting areas of potential conflict between protected-area administrators and local residents upon whom protected areas in Los Ríos have an impact, and perhaps elsewhere. Political and institutional prescriptions coming from shared myths and discourses about conservation and development can be "illegible" at the local level because humans find it difficult to see past their own ideological biases (Adger et al. 2001). Consensus analysis may be a tool with which PPA administrations in Los Ríos can rapidly assess their own cultural truths and compare them to those of local stakeholders, such as civic leadership and tourist services. We posit this assessment would also highlight areas of potential conflict in which additional dialogue, improved communication, and modified management strategies to benefit both public relations and the resource being protected.

Our results also suggest future efforts that employ cultural consensus analysis to assess and compare hegemonic ideology with local perspectives should consider iterative scale development and random sampling. Specifically, higher eigenratios and competency scores for conservation agents (i.e., the hegemonic ideology) would likely emerge if the scale was 
developed iteratively with modifications on successive versions of the instrument aimed at improving performance. We also note that purposive sampling limits inference to focal groups who are engaged with PPA administrations (Handwerker and Wozniak 1997). Future cultural consensus analysis studies employing large randomized samples may be representative of the population as a whole, but still allow for meaningful statistics on smaller subgroups. This development would obviously create logistical challenges, e.g., higher cost and developing a reliable sampling frame, and contest the conventional utility of this approach, and may be feasible and useful in some contexts, but requires further study.

Responses to this article can be read online at: http://www.ecologyandsociety.org/issues/responses. $\mathrm{php} / 7696$

\section{Acknowledgments:}

We thank all respondents for participating in this study and the entire research team for their hard work and dedication to this project. This work was conducted with financial support from Tourism Cares, the American Alpine Club, the Laarman International Gift Fund, and a Food and Agricultural Sciences National Needs International Dissertation Research Travel Allowance.

\section{LITERATURE CITED}

Adams, W. M., R. Aveling, D. Brockington, B. Dickson, J. Elliott, J. Hutton, D. Roe, B. Vira, and W. Wolmer. 2004. Biodiversity conservation and the eradication of poverty. Science 306 (5699):1146-1149. http://dx.doi.org/10.1126/science.1097920

Adger, W. N., T. A. Benjaminsen, K. Brown, and H. Svarstad. 2001. Advancing a political ecology of global environmental discourses. Development and Change 32(4):681-715. http://dx.doi. org/10.1111/1467-7660.00222

Anderson, R. 2007. Thematic content analysis: descriptive presentation of qualitative data. Wellknowing Consulting, Williams, Oregon, USA. [online] URL: http://www. wellknowingconsulting.org/publications/pdfs/ThematicContentAnalysis

Armesto, J. J., C. Smith-Ramirez, and R. Rozzi. 2001. Conservation strategies for biodiversity and indigenous people in Chilean forest ecosystems. Journal of the Royal Society of New Zealand 31(4):865-877. http://dx.doi.org/10.1080/03014223.2001.9517681

Barton, J. R., and Á. Román. 2012. Social movement strategies for articulating claims for socio-ecological justice: glocal asymmetries in the Chilean forestry sector. Globalizations 9 (6):869-885. http://dx.doi.org/10.1080/14747731.2012.739346

Bebbington, A. 1999. Capitals and capabilities: a framework for analyzing peasant viability, rural livelihoods and poverty. World Development 27(12):2021-2044. http://dx.doi.org/10.1016/s0305-750x (99)00104-7

Bishop, J., S. Pagiola, and N. Landell-Mills. 2002. Selling forest environmental services: market-based mechanisms for conservation and development. Earthscan, London, UK.
Borgatti, S. P., M. G. Everett, and L. C. Freeman. 2002. Ucinet for Windows: software for social network analysis. Analytic Technologies, Harvard, Massachusetts, USA.

Brechin, S. R., P. R. Wilshusen, C. L. Fortwangler, and P. C. West. 2002. Beyond the square wheel: toward a more comprehensive understanding of biodiversity conservation as social and political process. Society and Natural Resources 15(1):41-64. http://dx.doi. org/10.1080/089419202317174011

Brown, K. 2003. Integrating conservation and development: a case of institutional misfit. Frontiers in Ecology and the Environment 1(9):479-487. http://dx.doi.org/10.1890/1540-9295 (2003)001[0479:icadac]2.0.co;2

Carruthers, D. 2001. Environmental politics in Chile: legacies of dictatorship and democracy. Third World Quarterly 22:343-358. http://dx.doi.org/10.1080/01436590120061642

Clapp, R. A. 1998. Waiting for the forest law: resource-led development and environmental politics in Chile. Latin American Research Review 33(2):3-36.

Colchester, M. 1994. Salvaging nature, indigenous peoples, protected areas and biodiversity conservation. UNRISD Discussion Paper No. 55. United Nations Research Institute for Social Development, Geneva, Switzerland.

Coria, J., and E. Calfucura. 2012. Ecotourism and the development of indigenous communities: the good, the bad, and the ugly. Ecological Economics 73:47-55. http://dx.doi. org/10.1016/j.ecolecon.2011.10.024

Escobar, A. 1996. Construction nature: political elements for a post-structuralist ecology. Futures 28(4):325-343. http://dx.doi. org/10.1016/0016-3287(96)00011-0

Escobar, A. 2006. Difference and conflict in the struggle over natural resources: a political ecology framework. Development 49 (3):6-13. http://dx.doi.org/10.1057/palgrave.development.1100267

Escobar, A. 2011. Sustainability: design for the pluriverse. Development 54(2):137-140. http://dx.doi.org/10.1057/dev.2011.28

Faron, L. C. 1962. Symbolic values and the integration of society among the Mapuche of Chile. American Anthropologist 64 (6):1151-1164. http://dx.doi.org/10.1525/aa.1962.64.6.02a00020

Faugier, J., and M. Sargeant. 1997. Sampling hard to reach populations. Journal of Advanced Nursing 26:790-797. http://dx. doi.org/10.1046/j.1365-2648.1997.00371.x

Ferraro, P. J. 2001. Global habitat protection: limitations of development interventions and a role for conservation performance payments. Conservation Biology 15(4):990-1000. http://dx.doi.org/10.1046/j.1523-1739.2001.015004990.x

Ferraro, P. J., and R. D. Simpson. 2005. Protecting forests and biodiversity: are investments in eco-friendly production activities the best way to protect endangered ecosystems and enhance rural livelihoods? Forests, Trees and Livelihoods 15:167-181. http://dx. doi.org/10.1080/14728028.2005.9752518

Gatewood, J. B., and C. M. Cameron. 2009. Belonger perceptions of tourism and its impacts in the Turks and Caicos Islands. Ministry of Tourism, Turks and Caicos Islands, Grand Turk, Turks and Caicos Islands. [online] URL: http://www.lehigh.edu/ jbg1/ Perceptions-of-Tourism.pdf 
Hackel, J. D. 1993. Rural change and nature conservation in Africa: a case study from Swaziland. Human Ecology 21 (3):295-312. http://dx.doi.org/10.1007/bf00891541

Handwerker, W. P. 2002. The construct validity of cultures: cultural diversity, culture theory, and a method for ethnography. American Anthropologist 104:106-122. http://dx.doi.org/10.1525/ aa.2002.104.1.106

Handwerker, W. P., and D. F. Wozniak. 1997. Sampling strategies for the collection of cultural data: an extension of Boas's answer to Galton's problem. Current Anthropology 38(5):869-875. http:// dx.doi.org/10.1086/204675

Hughes, R., and F. Flintan. 2001. Integrating conservation and development experience: a review and bibliography of the ICDP Literature. Biodiversity and Livelihoods Issue Paper 3. International Institute for Environment and Development, London, UK. [online] URL: https://www.commdev.org/userfiles/ HUGHES, \%20R1-24.pdf

IBM Corporation. SPSS V21. IBM Corporation, Armonk, New York, New York, USA.

Johnson, J. C., and D. C. Griffith. 2010. Finding common ground in the commons: intracultural variation in users' conceptions of coastal fisheries issues. Society and Natural Resources 23 (9):837-855. http://dx.doi.org/10.1080/08941920802409585

Jones, N. A., H. Ross, T. Lynam, P. Perez, and A. Leitch. 2011. Mental models: an interdisciplinary synthesis of theory and methods. Ecology and Society 16(1): 46. [online] URL: http:// www.ecologyandsociety.org/vol16/iss1/art46/

Klubock, T. M. 2006. The politics of forests and forestry in Chile's southern frontier, 1880s-1940s. Hispanic American Historical Review 86(3):535-570. http://dx.doi.org/10.1215/00182168-2006-004

Mathevet, R., M. Etienne, T. Lynam, and C. Calvet. 2011. Water management in the Camargue Biosphere Reserve: insights from comparative mental models analysis. Ecology and Society 16(1): 43. [online] URL: http://www.ecologyandsociety.org/vol16/iss1/ $\underline{\operatorname{art} 43 /}$

McShane, T. O., P. D. Hirsch, T. C. Trung, A. N. Songorwa, A. Kinzig, B. Monteferri, D. Mutekanga, H. Van Thang, J. L. Dammert, M. Pulgar-Vidal, M. Welch-Devine, J. P. Brosius, P. Coppolillo, and S. O'Connor. 2011. Hard choices: making tradeoffs between biodiversity conservation and human well-being, Biological Conservation 144(3):966-972. http://dx.doi.org/10.1016/ j.biocon.2010.04.038

McShane, T. O., and S. A. Newby. 2004. Expecting the unattainable: the assumptions behind ICDPs. Pages 49-74 in $\mathrm{T}$. O. McShane and M. P. Wells, editors. Getting biodiversity projects to work: towards more effective conservation and development. Columbia University Press, New York, New York, USA.

Merino, M. E., and D. Quilaqueo. 2003. Ethnic prejudice against the Mapuche in Chilean society as a reflection of the racist ideology of the Spanish Conquistadors. American Indian Culture and Research Journal 27(4):105-116. [online] URL: http://isites. harvard.edu/fs/docs/icb.topic1270647.files/Ethnic $\% 20$ Prejudice $\%$ 20Against $\% 20$ the $\% 20$ Mapuche $\% 20$ in $\% 20$ Chilean $\% 20$ Society $\% 20$ as $\%$ 20a $\% 20$ Reflection $\% 20$ of $\% 20$ the $\% 20$ Racist $\% 20$ Ideology $\% 20$ of $\%$ 20the $\% 20$ Spanish $\% 20$ Conquistadors.pdf
Meza, L. 2009. Mapuche struggles for land and the role of private protected areas in Chile. Journal of Latin American Geography 8 (1):149-163.

Molares, S., and A. Ladio. 2012. Mapuche perceptions and conservation of Andean Nothofagus forests and their medicinal plants: a case study from a rural community in Patagonia, Argentina. Biodiversity and Conservation 21(4):1079-1093. http:// dx.doi.org/10.1007/s10531-012-0241-2

Mowforth, M., and I. Munt. 2008. Tourism and sustainability: development, globalisation and new tourism in the third world. Third edition. Routledge, New York, New York, USA.

Paolisso, M. 2007. Cultural models and cultural consensus of Chesapeake Bay blue crab and oyster fisheries. NAPA Bulletin 28:123-135. http://dx.doi.org/10.1525/napa.2007.28.1.123

Peters, J. 1998. Transforming the integrated conservation and development project (ICDP) approach: observations from the Ranomafana National Park project, Madagascar. Journal of Agricultural and Environmental Ethics 11:17-47. http://dx.doi. org/10.1023/A:1007796628731

Peterson, M. N., T. R. Peterson, M. J. Peterson, R. R. Lopez, and N. J. Silvy. 2002. Cultural conflict and the endangered Florida Key deer. Journal of Wildlife Management 66(4):947-968. http:// dx.doi.org/10.2307/3802928

Pratt, K. 2012. Fleshing out conservation: performative ecologies and embodied practice in Chilean temperate rainforest management. Dissertation, University of Minnesota, Minneapolis, Minnesota, USA. [online] URL: http://purl.umn.edu/139182

QSR International. NVivo 10 for Windows. QSR International, Doncaster, Australia.

Reyes-Garcia, V., E. Byron, V. Vadez, R. Godoy, L. Apaza, E. P. Limache, W. R. Leonard, and D. Wilkie. 2004. Measuring culture as shared knowledge: do data collection formats matter? Cultural knowledge of plant uses among Tsimane' Amerindians, Bolivia. Field Methods 16:135-156. http://dx.doi.org/10.1177/1525822X03262804

Rocha, J. M. 2005. Measuring traditional agro-ecological knowledge: an example from peasants in the Peruvian Andes. Field Methods 17(4):356-372. http://dx.doi.org/10.1177/1525822$\underline{\mathrm{x} 05275380}$

Romney, A. K., W. H. Batchelder, and S. C. Weller. 1987. Recent applications of cultural consensus theory. American Behavioral Scientist 31(2):163-177. http://dx.doi.org/10.1177/000276487031002003

Romney, A. K., S. C. Weller, and W. H. Batchelder. 1986. Culture as consensus: a theory of culture and informant accuracy. American Anthropologist 88(2):313-338. http://dx.doi.org/10.1525/ aa.1986.88.2.02a00020

Sachs, W. 2010. The development dictionary: a guide to knowledge as power. Second edition. Zed Books, New York, New York, USA.

Serenari, C. 2014. Conservation and development in Chilean Patagonia: assessing value orientations, cultural truths, and rural change in the context of public and private protected areas. Dissertation. North Carolina State University, Raleigh, North Carolina, USA. [online] URL: http://repository.lib.ncsu.edu/ir/ bitstream/1840.16/9496/1/etd.pdf 
Silva, E. 1997. The politics of sustainable development: native forest policy in Chile, Venezuela, Costa Rica and Mexico. Journal of Latin American Studies 29(2):457-493. http://dx.doi. org/10.1017/s0022216x97004756

Simeone, W. E., L. C. Naves, M. E. Lowe, G. Stickwan, E. M. Valentine, and J. Brady. 2010. Cultural models of Copper River salmon fisheries transmittal: draft of final report to the North Pacific Research Board for project No. 823. Technical Paper 351. Alaska Department of Fish and Game, Juneau, Alaska. [online] URL: http://doc.nprb.org/web/08 prjs/823 final $\% 20$ report $\% 20123010$. pdf

Stolton, S., K. H. Redford, and N. Dudley. 2014. The futures of privately protected areas. Protected Area Technical Report Series No. 1. IUCN, Gland, Switzerland. [online] URL: http://www. iucn.org/about/union/secretariat/offices/usa/?18399/The-Futuresof-Privately-Protected-Areas

Stone-Jovicich, S. S., T. Lynam, A. Leitch, and N. A. Jones. 2011. Using consensus analysis to assess mental models about water use and management in the Crocodile River catchment, South Africa. Ecology and Society 16(1): 45-69. [online] URL: http://www. ecologyandsociety.org/vol16/iss1/art45/

Wakild, E. 2009. Purchasing Patagonia: the contradictions of conservation in free market Chile. Pages 112-125 in W. L. Alexander, editor. Lost in the long transition: struggles for social justice in neoliberal Chile. Lexington Books, Lanham, Maryland, USA.

Weller, S. C. 2007. Cultural consensus theory: applications and frequently asked questions. Field Methods 19(4):339-368. http:// dx.doi.org/10.1177/1525822x07303502

Weller, S. C., and A. K. Romney, editors. 1988. Systematic data collection. Sage, Thousand Oakes, California, USA.

Wells, M. P., and T. O. McShane. 2004. Integrating protected area management with local needs and aspirations. Ambio 33 (8):513-519.

West, P., and D. Brockington. 2006. An anthropological perspective on some unexpected consequences of protected areas. Conservation Biology 20(3):609-616. http://dx.doi.org/10.1111/ j.1523-1739.2006.00432.x

West, P., J. Igoe, and D. Brockington. 2006. Parks and peoples: the social impact of protected areas. Annual Review of Anthropology 35(1):251-277. http://dx.doi.org/10.1146/annurev. anthro.35.081705.123308

Yung, L., W. A. Freimund, and J. M. Belsky. 2003. The politics of place: understanding meaning, common ground, and political difference on the Rocky Mountain Front. Forest Science 49 (6):855-866. 